\title{
CHEMOSPHERE
}

\section{Biomarker responses and reproductive toxicity of the effluent from a Chinese large sewage treatment plant in Japanese medaka (Oryzias latipes)}

\author{
Taowu Ma ${ }^{\text {a,b }}$, Xiaoqiong Wan ${ }^{\text {a }}$, Qinghui Huang ${ }^{\text {a }}$, \\ Zijian Wang $^{\mathrm{a}, *}$, Jiankang Liu ${ }^{\mathrm{c}}$ \\ a State Key Laboratory of Environmental Aquatic Chemistry, Research Center for Eco-Environmental Sciences, \\ Chinese Academy of Sciences, P.O. Box 2871, Beijing 100085, PR China \\ ${ }^{\mathrm{b}}$ College of Biology and Environmental Science, Jishou University, Jishou, 416000 Hunan, PR China \\ ${ }^{\mathrm{c}}$ Institute of Hydrobiology, Chinese Academy of Sciences, Wuhan 430072 Hubei, PR China
}

Received 23 December 2003; received in revised form 18 October 2004; accepted 16 November 2004

\begin{abstract}
The present study was conducted to assess the potential toxicity of the effluent from a large sewage treatment plant (GBD-STP) in Beijing. Japanese medakas (Oryzias latipes) at reproduction active period were exposed to a serial of graded concentrations of the effluent or $100 \mathrm{ng}^{-1}$ of $17-\alpha$-ethinylestradiol $\left(\mathrm{EE}_{2}\right.$, positive control). Growth, gonadosomatic index (GSI), hepatosomatic index (HSI), reproductive success, induction potency of vitellogenin (VTG) in male fish and that of 7-ethoxyresorufin-o-deethylase activity (EROD) in male fish liver were used as test endpoints. The growth suppression of fish was observed in a dose-dependent manner, resulting in significant differences in both body length and body weight of medaka above 5\% effluent. This effluent can inhibit the growth of gonad of medakas and are more sensitive to male than to female. At exposure concentration of $40 \%$ and higher, there was an unexpected decrease of HSI values, which may be resulted from sub-lethal toxicity of effluent to fish liver. VTG of plasma in males were induced in all exposure concentration levels, but not in a dose-dependent manner. The concentration of $5 \%$ effluent would be the lowest observed adverse effect level (LOAEL) affecting reproductive success when examining fertile individuals, fecundity and fertilization rate. The overt CYP1A response and higher reproductive toxicity may be indicative of low process efficiency of this STP.
\end{abstract}

(c) 2004 Elsevier Ltd. All rights reserved.

Keywords: Biomarker; Reproductive toxicity; Vitellogenin; CYP1A; Sewage effluent; Japanese medaka

\footnotetext{
* Corresponding author. Tel.: +86010628 49 140; fax: +86 01062923543.

E-mail addresses: mtw922@163.com (T. Ma),wangzj@, mail.rcees.ac.cn (Z. Wang).
}

\section{Introduction}

Municipal wastewater treatment plant (STP) effluents are one important source of toxic pollutants in the aquatic environment. In China, many new municipal STPs have been built to process the increasing industrial wastewaters and domestic wastewaters during the last 


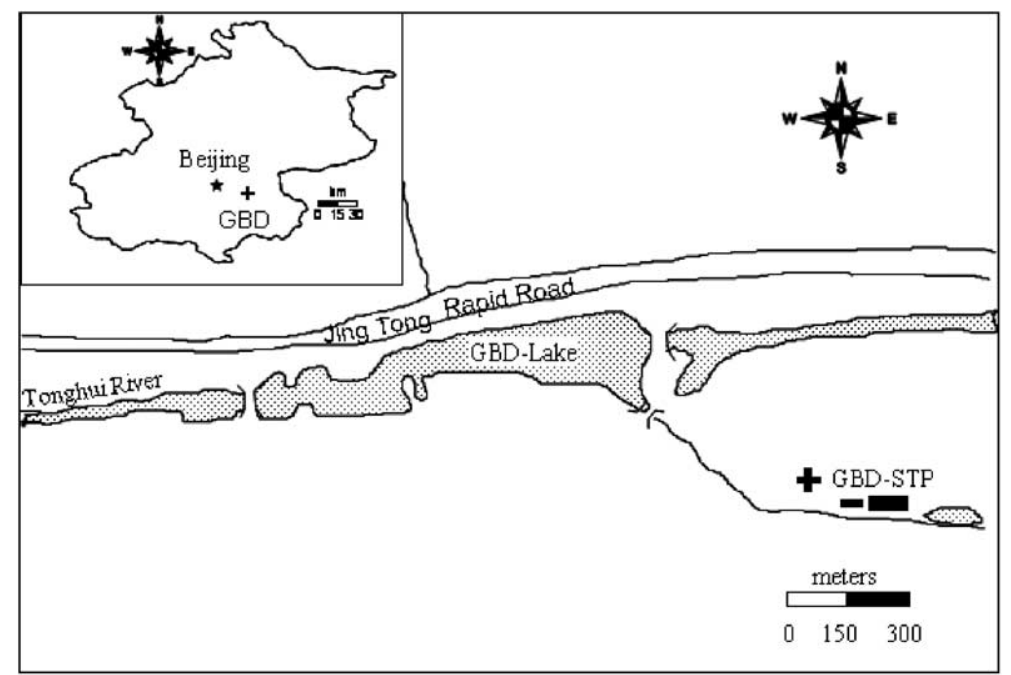

Fig. 1. Map of GBD-STP, GBD-lake and Tonghui River in Beijing (China) (the estimated volume of GBD-lake is $1.2 \mathrm{million}^{3}{ }^{3}$, and mean flow rate of Tonghui River is about $0.4 \mathrm{~m} / \mathrm{s}$ ).

few years, and a mass of sewage effluent were discharged into the receiving waters. However, there are many open questions of the sub-chronic and chronic effects of the effluents on the aquatic ecosystems. Freshwater bodies closing to densely populated areas may be particularly vulnerable to the presence of xenobiotics since the proximity to the sources of pollution and the low dilution factor of these waters makes the inhabiting fauna highly exposed, moreover, the purification role of STP has been questioned since, in some cases, they generate compounds with a higher toxicity than the parent compounds (Sole et al., 2001). It had been noted that estrogen conjugates, which are in biologically less active forms, could be deconjugated into free estrogens during the STP process (Desbrow et al., 1998). Several studies have revealed sewage effluents are estrogenic (indicated as vitellogenin induction) to male and juvenile fish and can also induce CYP1A response (McArdle et al., 2000; Sturve et al., 2000; Sole et al., 2002; Tilton et al., 2002; Sole et al., 2003). Limited field findings indicated that wildlife (mainly for fish) was experiencing compromised reproductive fitness (Lye et al., 1997). However, Giesy et al. (2003) indicated that the risk for estrogen agonist exposure below mid-Michigan wastewater treatment plants is small. The knowledge of the toxicity of STP effluents to aquatic organisms can provide an important baseline to guide the discharge control and ecological risk assessment of the effluents from STPs. However, it is very difficult to perform an effective field in situ investigation. The laboratory in vivo bioassay is usually an alterative approach to evaluate the potential toxicity effects of effluents to aquatic organisms.

The municipal STP selected for caring out present study is GBD-STP situating in Beijing, China. This
STP is the largest and most complex STP in Asia; it processes approximately 1 million $\mathrm{m}^{3}$ of sewage water per day and takes about $40 \%$ of total discharged sewage in Beijing; it receives both industrial wastewater and domestic wastewaters in the city. In the previous works, although some in vitro bioassays with respect to the toxicity of its effluents had been implemented (Wang et al., 2003), no information is given about the potential endocrine disruptive effects and other toxicity effects of this STP effluent on the level of individual or a population to aquatic species in its receiving waters such as Gaobeidian Lake and some rivers (Fig. 1). The present study focuses on aspects of reproductive success, estrogenic and CYP1A response of Japanese medaka (Oryzias latipes), a small ideal fish model that has been widely used to test endocrine disruptions of some chemical (Foran et al., 2000; Seki et al., 2002), exposed to different concentrations of effluent under laboratory conditions to determine the potential adverse health effects of effluent.

\section{Material and methods}

\subsection{Sewage effluent}

The secondary treated sewage effluent, which would be directly discharged into the receiving waters, was collected from GBD-STP and stored at less than $4{ }^{\circ} \mathrm{C}$ in the iced chambers. No treatment was done before use. The total volume of the effluent collected for testing is about 8001 , the volume of the glass vessel used for effluent containing is 201 , the glass vessel is airtight and there was no airspace, the effluent was collected 1 day before the start of the experiment. 


\subsection{Test fish and culture conditions}

Japanese medaka (Oryzias latipes) d-rR strain were originally provided by Y. Wakamatsu (Laboratory of Freshwater Fish Stock, Bioscience Center, Nagoya University, Japan), and a breeding stock of these medaka has been maintained for five generations in our laboratory before fish were used for the experiments. The fish were kept under a constant light-dark photoperiod of 16:8 $\mathrm{h}$ and a temperature of $25 \pm 1{ }^{\circ} \mathrm{C}$, which are suitable conditions for breeding. The brood stock was fed three times daily to satiation, once with Artemia nauplii (purchased from Tanggu, Tianjing, China), and twice with commercial fish flake food (TetraMin ${ }^{\circledR}$ ) consisting of $38 \%$ crude protein, $3 \%$ crude fat and $5 \%$ crude fiber.

Medakas selected for the study were approximately 80-day post-hatch and were fully mature (mean body weight, ơ $311 \pm 30 \mathrm{mg} \mathrm{SD}, q 305 \pm 20 \mathrm{mg} \mathrm{SD}$; mean body length, ơ $24.81 \pm 0.87 \mathrm{~mm} \mathrm{SD}$, ㅇ $24.04 \pm 0.62 \mathrm{~mm} \mathrm{SD})$. At the start of exposure, the body length and body weight were measured, 20 females and 20 males were arranged in each treatment, and then these selected reproductivelyactive medakas were exposed to a serial of graded effluent concentrations $(0 \%, 5 \%, 10 \%, 20 \%, 40 \%$ and $50 \%$ effluent) or a nominal concentration of $\mathrm{EE}_{2}\left(100 \mathrm{ng} \mathrm{l}^{-1}\right)$ as a positive control in 201 aquaria for 28 days. Fish were acclimatized for 2 days before exposure. The aquaria were supplied with dechlorinated tap water $\left(\mathrm{dH}_{2} \mathrm{O}\right)$, and airstones in aquaria provided air and a submersible heater was placed in each aquarium to maintain water temperature at $25 \pm 1^{\circ} \mathrm{C}$. All treatments were kept under a 16:8 h light: dark photoperiod and $100 \%$ exposure solution was renewed daily. Fish were fed exclusively with Artemia nauplii three times a day, and aquaria were cleared timely of residual food and debris.

\subsection{Reproduction experiments}

After 21-day exposure, the number of spawning females was recorded daily in each treatment. In the examination of reproductive success, five breeding sets were arranged for each treatment, two females and one male were assigned to each breeding set. Egg clutches were collected daily from females within $2-3 \mathrm{~h}$ of spawning till to the end of exposure. The egg number per egg clutch was counted, and then egg clutches were pooled and separated by rubbing the egg mass on a 40-mesh screen (Nimrod and Benson, 1998). The separated eggs were placed in petri dishes containing embryo-rearing solution, and checked for fertilization using a dissecting microscope. Fertilization is easily identified by the migration of oil globules to the vegetal pole (Kirchen and West, 1976). The embryo-rearing solution consisted of $1 \% \mathrm{NaCl}, 0.03 \% \mathrm{KCl}, 0.04 \% \mathrm{CaCl}_{2}, 0.163 \% \mathrm{MgSO}_{4}$, and a few drops of methylene blue in $100 \mathrm{ml}$ distilled water (Kirchen and West, 1976).

\subsection{Sampling and measurements}

On day 28, fish were anaesthetized in a bath of $1 \mathrm{~g} \mathrm{l}^{-1}$ methanesultfonate salt (MS-222, Sigma) buffered with $2 \mathrm{~g}^{-1} \mathrm{NaHCO}_{3}$ (Jensen et al., 2001), body length and body weight were measured, caudal peduncle was severed with a heparinized scissors and blood were collected from the caudal vein (ventral on the tail) with a heparinized glass capillary, and then transferred to a $0.6 \mathrm{ml}$ heparinized micro-centrifuge tube containing $20 \mu \mathrm{l}$ 0.4 M Tris-buffer (Allner et al., 1999). A protease inhibitor phenylmethylsulfonylfluoride (PMSF, Sigma) was added, and made the final concentration $1 \mathrm{mM}$. Micro-centrifuge tubes were agitated to mix heparin and PMSF with the blood sample and then centrifuged $\left(15 \mathrm{~min}\right.$ at $\left.4{ }^{\circ} \mathrm{C}, 10000 \times g\right)$ to separate plasma. The liver and gonad were removed and weighted for the determination of HSI and GSI indices $(100 \times$ liver or gonad weight/body weight). The plasma and excised livers were immediately frozen into liquid nitrogen and were then stored at $-80^{\circ} \mathrm{C}$ until analysis.

\subsection{Determination of VTG induction in plasma}

Induction of VTG was confirmed by separating $\beta$ mercaptoethanol-reduced plasma proteins on sodium dodecyl sulfate polyacryamide electrophoresis (SDSPAGE) gels. Separated proteins were stained with Coomassie Brilliant Blue (CBB, Sigma), and the bands were compared to high molecular weight protein markers (Amersham Pharmacia Biotech) and corresponding proteins present or absent in plasmas from normal male and vitellogenic female medaka. In the plasma of treated male Japanese medaka, molecular weight of induced additional protein is about $200 \mathrm{kDa}$ and consistent with previous report about VTG of Japanese medaka (Nishi et al., 2002). An excellent correlation $(r=0.99)$ was reported between the amount of VTG applied to the electrophoretic lanes and the integrated optical density (IOD) (Yeo and Mugiya, 1997). At present study, purified medaka VTG (our laboratory) was loaded into the gel, the coefficient between the integrated optical density (IOD) of the purified medaka VTG band and the amount of VTG applied to the electrophoretic lanes is 0.9925. Relative induced VTG levels of plasma were quantified by the IOD image analysis (Allner et al., 1999; Todorov et al., 2002) using an imaging and analysis software Quantity One version 4.3.0 (Bio-Rad). Briefly, prior to electrophoresis, blood plasma samples from all treatments were diluted as suitable factors to ensure clear bands and then were subjected to SDSPAGE, the integrated optical density (IOD) of the VTG band was measured by above computer program. The VTG level in plasma samples of effluent exposed fish was calculated by comparison with the blank control and the equivalent to the positive control. 


\subsection{EROD activity assay}

The individual liver tissue (approximately $0.02 \mathrm{~g}$ ) was homogenized in a glass-homogenizer with $180 \mu \mathrm{l}$ ice-cold phosphate buffer (PBS, pH 7.4) and $20 \mu \mathrm{l}$ of $10 \mathrm{mM}$ $\mathrm{PMSF}$, the homogenates were centrifuged at $10000 \times g$, $4{ }^{\circ} \mathrm{C}$ for $10 \mathrm{~min}$ in a centrifuge (Sigma, Germany) after homogenized in ice. The supernatants were used for EROD assay or protein content determination. The measurement was carried out on a fluorescence multi-well plate reader (Tecan-GENios, Finland) and calibration was done by a series of resorufin (RF) standards. The assay mixture consists of $950 \mu \mathrm{l}$ PBS ( $\mathrm{pH} 7.8), 10 \mu \mathrm{l}$ of $0.1 \mathrm{mM}$ ethoxyresorufin (ERF), and $10 \mu \mathrm{l}$ prepared liver homogenate supernatant sample. After mixing thoroughly for $5 \mathrm{~min}$, the reaction was initiated by adding $30 \mu \mathrm{l}$ of $1 \mathrm{mM}$ NADPH. The reaction temperature was controlled at $20 \pm 1{ }^{\circ} \mathrm{C}$. The reaction was stopped after $10 \mathrm{~min}$ by adding $200 \mu \mathrm{l}$ of methanol. The determination of each sample was carried out to measure the end product RF using the fluorescence multi-well plate reader at excitation wavelength $535 \mathrm{~nm}$ and emission wavelength $590 \mathrm{~nm}$. The protein concentration was assayed using a Bradford Assay Kit (Biyotime, China).

\subsection{Data analysis}

The graded concentration effluent groups were compared with the control group using Dunnett's multiple comparison tests. The statistical significance level was set at $p<0.05$ for all tests.

\section{Results and discussion}

\subsection{Growth, hepatosomatic index (HSI), and gonadosomatic index (GSI)}

The relative growth rates of medaka were calculated at the end of exposure (Table 1). The growth suppression of the fish was observed in a dose-dependent manner, resulting in significant decrease in both body length and body weight at or above 5\% effluent compared with those of the controls. Fish exposed to above $40 \%$ effluent displayed an apparent negative increase in body weight. The increased vitellogenesis (data showed in latter part), which is an energy-demanding anabolic process, may divert the energy resources from growth, and so is partially responsible for body weight loss. However, the observed reduction in body weight when exposed at higher concentrations may be also resulted from the decrease of their food intake.

The GSI values of both sexes decreased when concentration of effluent was higher than $5 \%$ (Table 1). The decrease of GSI with dilutions of effluent was in a dosedependent manner. Concentrations for which GSI values were significantly different from those of the controls, or the lowest observed effect concentration (LOEC), were $20 \%$ for females and $10 \%$ for male. The data suggested that the effluents from GBD-STP could inhibit the growth of gonad of medakas and males are more sensitive to effluent than female. The HSI values of females and males increased significantly when exposed to $10 \%$ and $20 \%$ effluent, respectively (Table 1 ). It is obvious that the HSI values in both sexes exposed $20 \%$ effluent were significantly different from the controls, resulting mainly from the rapid decrease of body weight. However, at exposure concentration of $40 \%$ and higher, there was a decrease of HSI values. The decrease of HSI value exposed to high concentrations $(\geqslant 40 \%)$ of the effluents may be caused by sub-lethal toxicity of the effluent and could be proved in the pathologic observation of liver. The grossly visible lesions of the liver, presented as the slight white other than the normal orchid, occurred at concentration of $40 \%$. Variation of HSI at higher concentrations of effluent could be the joint effects of loss of body weight and liver intoxication.

\subsection{VTG induction of plasma}

Induction of VTG in male fish was given in Table 2. The results indicated that plasma VTG in males was induced in all concentration levels, but not in a dosedependent manner. At $20 \%$ effluent, there is a maximal VTG induction $(1722 \%$ of control or equivalent to 0.70 of $\mathrm{EE}_{2}$ induction), which are significantly different from those of the controls. It is noticeable that relatively higher levels of induction were observed even at lower concentrations (1474\% and $1409 \%$ of the controls at $5 \%$ and $10 \%$, respectively). In previous work, Harries et al. (1999) found that a 25\% dilution of a STP effluent in UK completely removed its capacity to induce VTG in male trout. This difference of estrogenic response among different STPs may be due to differences among composition and concentrations of EDs in effluent water, treatment procedure, as well as species for testing. In case of GBD-STP, it receives not only domestic sewage (about $70 \%$ of total influent), but also receives considerable amount of effluents from industrial wastewater treatment facilities. These industrial wastewaters contained EDs-like chemicals (data will be published in separated papers). Also, the secondary treatment processes could result in enhanced deconjugation of the conjugated steroids derived from human and animal excretion, thereby increasing estrogenicity.

However, at $40 \%$ and $50 \%$ effluent, a decrease of VTG induction with $926 \%$ and $843 \%$, respectively, was observed in comparison with lower concentrations of effluent. Similar observation was given in largemouth bass in which higher concentration effluent exposure apparently reduced VTG induction (Sepulveda et al., 2003). As mentioned above, sub-lethal toxicity were observed 
Table 1

The relative growth rate (RGR), gonadosomatic index (GSI) and hepatosomatic index (HSI) of Japanese medaka

\begin{tabular}{|c|c|c|c|c|c|c|c|c|}
\hline \multirow[t]{2}{*}{ Sex } & \multirow[t]{2}{*}{ Parameters } & \multicolumn{6}{|c|}{ Effluent concentration $(\%)$} & \multirow[t]{2}{*}{$\mathrm{EE}_{2}\left(100 \mathrm{ng} \mathrm{l}^{-1}\right)$} \\
\hline & & 0 & 5 & 10 & 20 & 40 & 50 & \\
\hline \multirow[t]{7}{*}{ Female } & $\operatorname{RGR}(\mathrm{BL})^{\mathrm{a}}$ & 16.96 & 8.61 & 7.29 & 5.20 & 3.44 & 2.91 & 12.67 \\
\hline & $\mathrm{RGR}(\mathrm{BW})^{\mathrm{b}}$ & 41.83 & 21.95 & 7.62 & 9.19 & -6.90 & -7.41 & 33.97 \\
\hline & Mean BW (g) & $0.429 \pm 0.033$ & $0.378 \pm 0.051$ & $0.349 \pm 0.048$ & $0.343 \pm 0.053$ & $0.279 \pm 0.066$ & $0.273 \pm 0.059$ & $0.366 \pm 0.034$ \\
\hline & Mean GW (g) & $0.039 \pm 0.006$ & $0.033 \pm 0.011$ & $0.027 \pm 0.008$ & $0.025 \pm 0.006$ & $0.016 \pm 0.006$ & $0.016 \pm 0.007$ & $0.025 \pm 0.008$ \\
\hline & GSI & $9.06 \pm 1.39(16)$ & $8.66 \pm 2.90(20)$ & $7.81 \pm 2.31(18)$ & $7.31 \pm 1.77(16)^{*}$ & $5.70 \pm 2.08(17)^{*}$ & $5.49 \pm 2.70(16)^{*}$ & $6.91 \pm 2.06(17)^{*}$ \\
\hline & Mean LW (g) & $0.019 \pm 0.004$ & $0.018 \pm 0.003$ & $0.019 \pm 0.002$ & $0.018 \pm 0.003$ & $0.012 \pm 0.002$ & $0.013 \pm 0.003$ & $0.017 \pm 0.003$ \\
\hline & HSI & $4.50 \pm 0.94(16)$ & $4.63 \pm 0.88(20)$ & $5.44 \pm 0.47(18)^{*}$ & $5.37 \pm 0.99(16)^{*}$ & $4.15 \pm 0.72(17)$ & $4.28 \pm 0.89(16)$ & $4.53 \pm 0.68(17)$ \\
\hline \multirow[t]{7}{*}{ Male } & RGR(BL) & 17.74 & 11.56 & 12.33 & 5.86 & 4.27 & 3.46 & 14.52 \\
\hline & RGR(BW) & 49.48 & 28.17 & 14.43 & 10.31 & -4.53 & -7.19 & 32.68 \\
\hline & Mean BW (g) & $0.463 \pm 0.036$ & $0.418 \pm 0.048$ & $0.373 \pm 0.055$ & $0.335 \pm 0.045$ & $0.306 \pm 0.032$ & $0.289 \pm 0.047$ & $0.372 \pm 0.037$ \\
\hline & Mean GW (g) & $0.006 \pm 0.001$ & $0.005 \pm 0.001$ & $0.004 \pm 0.001$ & $0.003 \pm 0.0005$ & $0.003 \pm 0.0005$ & $0.002 \pm 0.0006$ & $0.002 \pm 0.0005$ \\
\hline & GSI & $1.37 \pm 0.16(16)$ & $1.22 \pm 0.22(20)$ & $1.14 \pm 0.27(20)^{*}$ & $0.91 \pm 0.14(20)^{*}$ & $0.89 \pm 0.16(20)^{*}$ & $0.83 \pm 0.22(18)^{*}$ & $0.51 \pm 0.14(17)^{*}$ \\
\hline & Mean LW (g) & $0.017 \pm 0.003$ & $0.018 \pm 0.003$ & $0.017 \pm 0.006$ & $0.016 \pm 0.004$ & $0.011 \pm 0.002$ & $0.010 \pm 0.001$ & $0.016 \pm 0.003$ \\
\hline & HSI & $3.75 \pm 0.61(16)$ & $4.17 \pm 0.69(20)$ & $4.48 \pm 1.50(20)$ & $4.69 \pm 1.11(20)^{*}$ & $3.25 \pm 0.64(20)^{*}$ & $3.55 \pm 0.45(18)$ & $4.42 \pm 0.75(17)$ \\
\hline
\end{tabular}

GSI $=($ gonad weight $/$ body weight $) \times 100 \%$; HSI = (liver weight/body weight $) \times 100 \%$, data expressed as mean \pm SD. GW, gonad weight; LW, liver weight.

* Significantly different from control group ( $0 \%$ effluent) (Dunnett's test, $p<0.05)$.

(Mean final body length - mean initial body length)/mean initial body length; BL: body length.

b (Mean final body weight - mean initial body weight)/mean initial body weight; BW: body weight. 
Table 2

Plasma VTG induction of male fish exposed to graded concentrations of effluent and $\mathrm{EE}_{2}$

\begin{tabular}{lrll}
\hline Groups & \multicolumn{1}{c}{$\begin{array}{l}\text { Plasma } \\
\text { VTG }^{\mathrm{a}}\end{array}$} & $\begin{array}{l}\text { \% of } \\
\text { control }^{\mathrm{b}}\end{array}$ & VTG-EQ $^{\mathrm{c}}$ \\
\hline 0\% Effluent (control) & $2.3 \pm 0.90$ & - & 0.04 \\
$5 \%$ Effluent & $33.9 \pm 0.96$ & 1474 & 0.60 \\
$10 \%$ Effluent & $32.4 \pm 2.82$ & 1409 & 0.57 \\
$20 \%$ Effluent & $39.6 \pm 1.56$ & 1722 & 0.70 \\
$40 \%$ Effluent & $21.3 \pm 1.40$ & 926 & 0.38 \\
$50 \%$ Effluent & $19.4 \pm 0.68$ & 843 & 0.34 \\
$100 \mathrm{ng} \mathrm{l}^{-1} \mathrm{EE}_{2}$ & $56.4 \pm 2.98$ & 2452 & - \\
\hline
\end{tabular}

${ }^{\text {a }}$ Expressed as density units of VTG staining from plasmas samples of male medaka, each value represents the mean of 3 samples $\pm \mathrm{SD}$.

b $\%$ of control $=($ effluent mean/control mean $) \times 100$.

${ }^{\mathrm{c}}$ VTG-EQ $=($ effluent mean/EE 2 group mean $)$.

at concentration levels higher than $40 \%$ and inflammatory reaction could be observed in fish liver, which was in accord with the decreased HSI values and loss of body weight (Table 1). In fact, a parallel variation of VTG level of plasma and HSI values was reported in a field survey in the UK estuarine and marine environments (Allen et al., 1999). At higher concentrations, significant stresses of toxic substances, such as ammonia (Garric et al., 1996), and consequently the impairment of liver function might occur such that vitellogenesis was impaired.

\subsection{Reproductive success}

The number of spawning females, fecundity and fertilization rates of $\mathrm{F} 1$ generation in the last 7 days of exposure were given in Table 3 . The number of spawning females in the groups exposed to effluent was reduced significantly, but not in dose-dependent manner. At 5-20\% concentration levels, there were a steady number of spawning females with an average of 10 individuals per
Table 3

The number of spawning females, fecundity and fertilization rate within 7 days before the end of exposure

\begin{tabular}{llll}
\hline & $\begin{array}{l}\text { Number of } \\
\text { spawning } \\
\text { females }\end{array}$ & Fecundity $^{\mathrm{a}}$ & $\begin{array}{l}\text { Fertilization } \\
\text { rate (\%) }\end{array}$ \\
\hline $0 \%$ Effluent & $15.6 \pm 1.5(3)$ & $13.9 \pm 1.2(5)$ & $86.2 \pm 7.3(5)$ \\
$5 \%$ Effluent & $9.8 \pm 1.8(3)^{*}$ & $14.6 \pm 2.4(5)$ & $85.1 \pm 5.5(5)$ \\
$10 \%$ Effluent & $10.4 \pm 1.8(3)^{*}$ & $12.0 \pm 2.1(5)$ & $84.5 \pm 2.0(5)$ \\
$20 \%$ Effluent & $10.8 \pm 0.8(3)^{*}$ & $11.4 \pm 1.9(5)$ & $78.6 \pm 2.7(5)$ \\
$40 \%$ Effluent & $5.6 \pm 1.5(3)^{*}$ & $9.6 \pm 1.1(5)^{*}$ & $59.0 \pm 16.6(5)^{*}$ \\
$50 \%$ Effluent & 0 & 0 & 0 \\
$100 \mathrm{ng} \mathrm{l}^{-1} \mathrm{EE}_{2}$ & $6.4 \pm 1.7(3)^{*}$ & $10.2 \pm 2.9(5)^{*}$ & $75.4 \pm 4.9(5)^{*}$ \\
\hline
\end{tabular}

Data are expressed as means \pm SD. Number of spawning females represent the mean ( $n=3$ experiments \pm SD).

* Significantly different from control group $(0 \%$ effluent $)$ (Dunnett's test, $p<0.05$ ).

${ }^{a}$ Expressed as egg number per day and female.

day; less than six females laid eggs at $40 \%$ concentration and no spawning female was observed at $50 \%$ concentration. These results suggested that there seemed to be a significantly compromised population reproductive fitness under the exposure of effluent. Under the condition of persistent exposure, the concentration of $50 \%$ effluent is the extinct point of population. Significant decreases of both fecundity and fertilization rates in $\mathrm{F} 1$ generation were observed at $40 \%$ concentration level. In contrast, the number of spawning females, fecundity and fertilization rates of $\mathrm{F} 1$ generation in positive controls were significantly decreased. In the present study, the concentration of 5\% GBD-STP effluent may be the lowest observed adverse effect level (LOAEL) which compromised the reproductive success of medaka.

\subsection{Liver EROD induction}

EROD activities were obviously induced in effluentexposed medakas (Fig. 2). Significant differences were

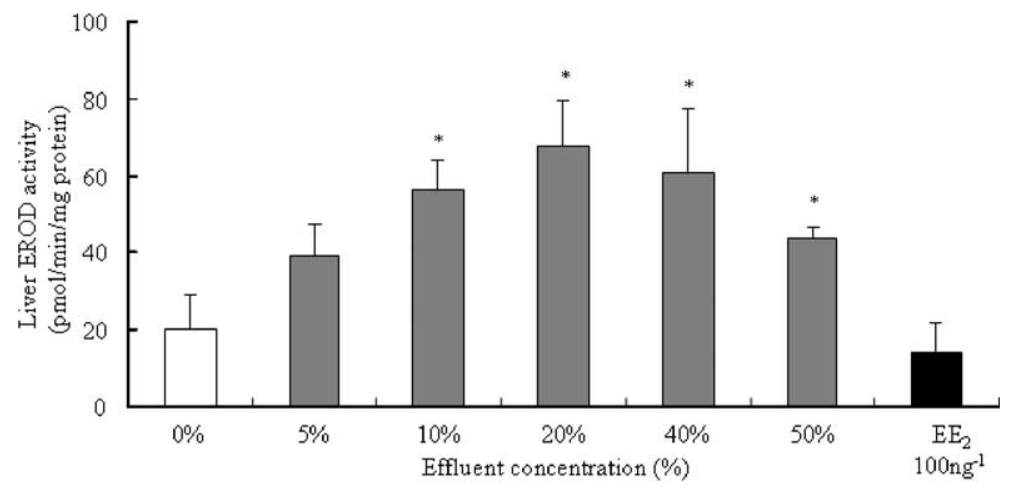

Fig. 2. Induction of liver EROD activity in male Japanese medaka (Oryzias latipes) following exposure. Data are given from 10 individuals in each treatment. Significance between controls and exposed groups by Dunnet's test $\left({ }^{*} p<0.05\right)$. 
observed at concentration of $10 \%$ and higher when compared to the controls, indicating the presence of CYP1A inducers in the effluents. The investigations of Gossett et al. (1983) showed that municipal STP effluents could contain $\mathrm{ng}^{-1}$ levels of CYP1A inducers, such as polycyclic aromatic hydrocarbons (PAHs) and polychlorinated biphenyls (PCBs). In our previous work in GBD-STP (Wang et al., 2001), CYP1A inducers such as PCBs and PAHs could hardly be removed from the effluent through activated sludge process. This may be an indication that the activated sludge process in GBD-STP is not running correctly or that suspended solids are not being removed efficiently. It was found that the dose-dependent manner of EROD induction was comparable to the induction of VTG (Table 2), namely, both VTG induction and EROD activity simultaneously elevated in effluent-exposed medakas. A similar phenomenon was observed in sunshine bass (McArdle et al., 2000). However, Sturve et al. (2000) have shown that EROD activity in the exposed groups was lower than that in the controls. The discrepancies of findings among different authors could be an indication of different characteristics of the influents. EROD activities of fish exposed to $100 \mathrm{ng} \mathrm{l}^{-1}$ of $\mathrm{EE}_{2}$ were lower than those of controls (no induction), this indicted that $\mathrm{EE}_{2}$ might seem to decrease EROD activity in medaka. It is known that some estrogen such as estradiol can suppress EROD activity in fish (McArdle et al., 2000). Additionally, compared to other authors' study, the control EROD activity seems high. It has been reported that EROD activity in the liver microsomal fraction of unexposed medaka (10-month-old) could reach about $10 \mathrm{pmol} / \mathrm{min} / \mathrm{mg}$ of protein (Carlson et al., 2002). This difference may produce from the course of process to microsomal pellets, different measure equipments (such as 96-well microtitre plate, colorimetric tubes, Fluorescence Reader) and the developmental stages of fish.

\section{Conclusions}

Reproductively active medaka exposed to effluent from a large STP in Beijing and $\mathrm{EE}_{2}$ revealed significant suppression of growth, impairment of liver function and reproduction. Above the concentration of $5 \%$ effluent, there were higher estrogenic and CYP1A response. Effluent concentrations higher than $20 \%$ will directly lead to dysfunction of liver and gonad. It may be predicted through the extrapolation of the present results to the receiving water that fish inhabiting in the proximity of GBD-STP or nearby GBD Lake is experiencing adverse health and reproduction impairment. The overt CYP1A response and higher reproductive toxicity may be indicative of low process efficiency of GBD-STP.

\section{Acknowledgement}

This work is supported by Chinese Academy of Sciences (KZCX2-414), 863 projects (2001AA6406010) and the Natural Science Foundation of China (20237010).

\section{References}

Allen, Y., Matthiessen, P., Scott, A.P., Haworth, S., Feist, S., Thain, J.E., 1999. The extent of oestrogenic contamination in the UK estuarine and marine environments - further surveys of flounder. Sci. Total Environ. 233, 5-20.

Allner, B., Wegener, G., Knacker, T., Stahlschmidt-Allner, P., 1999. Electrophoretic determination of estrogen-induced protein in fish exposed to synthetic and naturally occurring chemicals. Sci. Total Environ. 233, 21-30.

Carlson, E.A., Li, Y., Zelikoff, J.T., 2002. Exposure of Japanese medaka (Oryzias latipes) to benzo[a]pyrene suppresses immune function and host resistance against bacterial challenge. Aquat. Toxicol. 56, 289-301.

Desbrow, C., Routledge, E.J., Brighty, G.C., Sumpter, J.P., Waldock, M., 1998. Identification of estrogenic chemicals in STP effluents. 1. Chemical fractionation and in vivo biological screening. Envion. Sci. Technol. 32, 1549-1558.

Foran, C.M., Bennett, E.R., Benson, W.H., 2000. Exposure to environmentally relevant concentrations of different nonylphenol formulations in Japanese medaka. Mar. Environ. Res. 50, 135-139.

Garric, J., Vollat, B., Nguyen, D.K., Bray, M., Migeon, B., Kosmala, A., 1996. Ecotoxicological and chemical characterization of municipal wastewater treatment plant effluents. Water Sci. Technol. 33, 83-91.

Giesy, J.P., Snyder, E.M., Nichols, K.M., Snyder, S.A., Villalobos, S.A., Jones, P.D., Fitzgerald, S.D., 2003. Examination of reproductive endpoints in goldfish (Carassius auratus) exposed in situ to municipal sewage treatment plant effluent discharges in Michigan, USA. Environ. Toxicol. Chem. 22, 2416-2431.

Gossett, R.W., Brown, D.A., Young, D.R., 1983. Predicting the bioaccumulation of organic compounds in marine organisms using octanol/water partition coefficients. Mar. Pollut. Bull. 14, 387-392.

Harries, J.E., Janbakhsh, A., Jobling, S., Matthiesson, P., Sumpter, J.P., Tyler, C.R., 1999. Estrogenic potency of effluent from two sewage treatment works in the United Kingdom. Environ. Toxicol. Chem. 18, 932-937.

Jensen, K.M., Korte, J.J., Kahl, M.D., Pasha, M.S., Ankley, G.T., 2001. Aspects of basic reproductive biology and endocrinology in the fathead minnow (Pimephales promelas). Comp. Biochem. Physiol. C 128, 127-141.

Kirchen, R.V., West, W.R., 1976. The Japanese Medaka: Care and Development. Carolina Biological Supply Company, Burlington, North Carolina, USA.

Lye, C.M., Frid, C.L.J., Gill, M.E., McCormick, D., 1997. Abnormalities in the reproductive health of flounder (Platichthys flesus) exposed to effluent from a sewage treatment work. Mar. Pollut. Bull. 34, 34-41.

McArdle, M., Elskus, A., McElroy, A., Larsen, B., Benson, W., Schlenk, D., 2000. Estrogenic and CYP1A response of 
mummichogs and sunshine bass to sewage effluent. Mar. Environ. Res. 50, 175-179.

Nimrod, A.C., Benson, W.H., 1998. Reproduction and development of Japanese medaka following an early life stage exposure to xenoestrogens. Aquat. Toxicol. 44, 141-156.

Nishi, K., Chikae, M., Hatano, Y., Mizukami, H., Yamashita, M., Sakakibara, R., Tamiya, E., 2002. Development and application of a monoclonal antibody-based sandwich ELISA for quantification of Japanese medaka (Oryzias latipes) vitellogenin. Comp. Biochem. Physiol. C 132, 161169.

Seki, M., Yokota, H., Matsubara, H., Tsuruda, Y., Maeda, M., Tadokoro, H., Kobayashi, K., 2002. Effect of ethinylestradiol on the reproduction and induction of vitellogenin and testis-ova in medaka (Oryzias latipes). Environ. Toxicol. Chem. 21, 1692-1698.

Sepulveda, M.S., Quinn, B.P., Denslow, N.D., Holm, S.E., Gross, T.S., 2003. Effects of pulp and paper mill effluents on reproductive success of largemouth bass. Environ. Toxicol. Chem. 22, 205-213.

Sole, M., Barcelo, D., Porte, C., 2002. Seasonal variation of plasmatic and hepatic vitellogenin and EROD activity in carp, Cyprinus carpio, in relation to sewage treatment plants. Aquat. Toxicol. 60, 233-248.

Sole, M., Porte, C., Barceló, D., 2001. Analysis of the estrogenic activity of sewage treatment works and receiving waters using vitellogenin induction in fish as a biomarker. Trends Anal. Chem. 20, 518-525.

Sole, M., Raldua, D., Barcelo, D., Porte, C., 2003. Long-term exposure effects in vitellogenin, sex hormones, and bio- transformation enzymes in female carp in relation to a sewage treatment works. Ecotoxicol. Environ. Saf. 56, 373380.

Sturve, J., Parkkonen, J., Förlin, L., 2000. Biomarker responses in rainbow trout (Oncorhynchus mykiss) exposed to sewage treatment plant effluent. Mar. Environ. Res. 50, 431-441.

Tilton, F., Benson, W.H., Schlenk, D., 2002. Evaluation of estrogenic activity from a municipal wastewater treatment plant with predominantly domestic input. Aquat. Toxicol. 61, 211-224.

Todorov, J.R., Elskus, A.A., Schlenk, D., Ferguson, P.L., Brownawell, B.J., McElroy, A.E., 2002. Estrogenic responses of larval sunshine bass (Morone saxatilis $\times M$. Chrysops) exposed to New York city sewage effluent. Mar. Environ. Res. 54, 691-695.

Wang, C., Wang, Y., Kiefer, F., Yediler, A., Wang, Z., Kettrup, A., 2003. Ecotoxicological and chemical characterization of selected treatment process effluent of municipal sewage treatment plant. Ecotoxicol. Environ. Saf. 56, 211217.

Wang, Y., Wang, Z., Ma, M., Wang, C.X., Zheng, M., 2001. Monitoring priority pollutants in a sewage treatment process by dichloromethane extraction and triolein-semipermeable membrane device (SPMD). Chemosphere 43, 339-346.

Yeo, I.Y., Mugiya, Y., 1997. Effects of extracellular calcium concentrations and calcium antagonists on vitellogenin induction by $17-\beta$-estradiol in primary hepatocyte culture in the rainbow trout (Oncorhynchus mykiss). Gen. Comp. Endocrinol. 105, 294-301. 